\title{
Global Relative Prices in the Face of a Pollution Transfer Problem
}

\author{
John Dogbey \\ Department of Economics, University of Nebraska at Omaha, Omaha, USA \\ Email: jdogbey@unomaha.edu
}

Received September 22, 2012; revised October 23, 2012; accepted November 25, 2012

\begin{abstract}
This study focuses on the relationship between trade and relative prices of pollution intensive goods. Seminal to this idea is the transfer problem. It is based on the idea that environmental quality of two countries that engage in trade could be affected and this could also have possible environmental quality transfer effects in a third country (geographic neighbors or trade partners) and a result, terms of trade effects. The paper makes the case that whether the relative price of a pollutant would suffer during trade will depend on the kind of pollutant it is, distance between the countries involved, countries' marginal propensity to consume and substitutability of the good. The nature of the pollutant (whether it is spatially separable in production and or consumption) determines whether it can spillover to trade neighbors or whether it is transferable to a trade partner with ramifications to its relative price. The paper uses indirect utility functions and compensated demand functions to analyze the terms of trade effects.
\end{abstract}

Keywords: Relative Prices; Spatially Separable; Trade; Substitutability; Pollutant; Transfers

\section{Introduction}

The debate on the role of trade in environmental pollution has attracted a lot of attention in recent years. Many believe that trade has a debilitating effect on the environment and others hold contrary views. For example, research has been done to determine whether reduction in trade barriers alters the composition of economic activity, or leads to a change in the techniques of production and thus have an effect on the environment. The environmental impacts of trade policies as well the trade impacts of environmental policies have also been investigated. These researchers find that trade liberalization may increase specialization in sectors that cause little pollution. These studies include Grossman and Krueger [1], and Huang and Labys [2].

The relationship between economic growth and environmental pollution has also gained much attention. Researchers find that a liberal trade regime leads to income growth and that economic growth reduces pollution once a country reaches a certain income threshold. Other findings are that as trade increases and growth increases, environmental pollution also increases. The other side of the coin is that environmental policies reduce trade and growth. Stricter environmental standards are also considered necessary for a U-shaped relationship between pollution and income during growth as discussed in Grossman and Krueger [1], Huang and Labys [2], and Grossman and Krueger [3], and McConnell [4].

On the effect of trade on countries' Environmental Kuznets Curve (EKC), a myriad of research has been carried out. A theoretical work finds that during the transition from autarky to international trade, the EKC Ushape relationship may hold for a cross-section of countries but may not hold for individual economies. The extent to which consumer preferences and structures such as education level, sectoral composition of the economy, and unemployment can spatially and intertemporally affect the EKC relationship has been explored with the result that the level of income at which households decide to reduce their exposure to pollution depends on the nature of the pollution. For goods that are spatially separable (i.e., goods which do not generate pollution during either their production or consumption), such as $\mathrm{SO}_{2}$ and $\mathrm{PM}_{10}$, there is significant evidence of such relationship while there is little evidence for nonspatially separable pollutants such as $\mathrm{CO}_{3}, \mathrm{O}_{3}$ and NOx. Khanna [5], and Khanna and Plassmann [6] document these views.

Other researchers in the area of welfare and trade analyze the welfare effects that arise when rich countries make bilateral or multilateral transfers to poor countries and conclude that there is a transfer problem in that poor countries get impoverished when they receive transfers from rich countries. These researchers include Bandyopadhay and Majumdar [7], and Bandyopadhyay and 
Munemo [8], and Bhagwati, Brecher, and Hatta [9], and Bhagwati and Brecher [10,11].

While a plethora of literature looks at the link between trade and the environment, or trade and relative prices, no research has made the link between pollution, trade and relative prices. This paper attempts to fill the gap by providing a comparative statistics analysis to examine what happens to relative prices during trade when the good in question is a pollutant. It establishes a relationship between pollution, trade, welfare and relative prices. Thus, it addresses the issue of global welfare effects or terms of trade effects when countries engage in trade involving pollutants. The rest of this paper is organized as follows: In the next section I present the models and derive the results, followed by the comparison of the results and intuition behind them in Section 3, then present the concluding remarks and policy recommendations in Section 4.

\section{The Model}

\subsection{The General Model}

This paper uses compensated demand functions, indirect utility functions and the overspending functions of countries to analyze bilateral trade in a pollutant in a multilateral context. This model assumes a three-country world: countries $\alpha, \gamma, \beta$, namely the developed country, the developing country and the non-participant; only countries $\gamma$ and $\beta$ could be neighbors (the developed country's aim is to transfer pollution, so it can only engage in such a trade with a developing country that is not its neighbor). The model also assumes a two-good world: Good $X$ and $\operatorname{good} Y$; $\operatorname{good} X$ is the pollutant.

The paper considers three cases of the pollutant and hence three models. The first two cases relate to a situation where consumption or production of the good is spatially separable (either consumption or production does not generate pollution) while the third case relates to a situation where both production and consumption are non-spatially separable. Case 1 involves a situation where only consumption generates pollution (only consumption is non-spatially separable) and it is assumed that the developed country transfers pollution by exporting good $X$ to the developing country. Case 2 is the one in which only the production of good $X$ generates pollution (only production is non-spatially separable), and the developed country is assumed to transfer pollution by exporting production or the pollution generating activities to the developing country, $\gamma$. Case 3 is a scenario where both the production and consumption of good $X$ generates pollution (consumption and production are both nonspatially separable). The developed country is assumed to still export production to the developing country, with the possibility of importing the finished goods, thereby transferring the production emissions.

The cases above thus result in three models. The overspending (indirect utility) function of each country, $c^{i}$, is its cost (expenditure) less its revenue.

Let $q^{i}=$ the relative price of $\operatorname{good} X$;

$u^{i}=$ the welfare level of country $i$;

$P=$ the value (cost) of the pollution in terms of good $Y$;

$\delta=$ inverse distance between country $\beta$ and $\gamma ; 0 \leq \delta<$ 1

$e^{i}\left(q, u^{i}\right)=$ the expenditure function of country $i$;

$r^{i}(q)=$ the revenue function of country $i$;

$x^{i}\left(q, u^{i}\right)=$ the compensated import-demand function of good $X$ by country $i$.

Then the overspending function in autarky is given by: $c^{i}\left(q, u^{i}\right)=e^{i}\left(q, u^{i}\right)-r^{i}(q)^{1} ; i=\alpha, \beta, \lambda$.

\subsection{Case 1: Only Consumption Generates Pollution}

Introducing trade in good $X$, the budget equation for each country will include $P$ (the volume of trade in the pollutant), which will be adding to the benefit (revenue) component of the developed country (the exporter), but reducing the revenue component (or adding to the cost component) of the developing country (importer) and the non-participant (depending on the distance between the importer and the non-participant). In other words, the export of the pollutant reduces the overspending function of country $\alpha$ but increases the overspending functions of countries $\gamma$ and $\beta$. The model comprises of the budget equations of the three countries and the market clearing equation of $\operatorname{good} X$ :

$$
\begin{gathered}
c^{\alpha}\left(q, u^{\alpha}\right)-P=0 \\
c^{\beta}\left(q, u^{\beta}\right)+\delta P=0 \\
c^{\gamma}\left(q, u^{\gamma}\right)+P=0 \\
x^{\alpha}\left(q, u^{\alpha}\right)+x^{\beta}\left(q, u^{\beta}\right)+x^{\gamma}\left(q, u^{\gamma}\right)=0
\end{gathered}
$$

As the developed and developing country trade the production and, hence, the consumption of the pollutant increases (so $P$ increases). Taking total differentials of Equations (2.1)-(2.4) and augmenting gives:

\footnotetext{
${ }^{1}$ During trade, a country's overspending function will increase (decrease) if it is importing (exporting) good $X$.

${ }^{2}$ The budget equation of the non-participant is affected not by the full value of the pollution, but by a fraction. The longer the distance between the non-participant and its neighbor, the smaller the value of $\delta$ and hence the smaller the value of the pollution transfer or spillover. When $\delta$ approaches zero, the non-participant's overspending function and budget equation will be the same.

${ }^{3}$ By Walras Law, the market clearing equation of good $Y$ is omitted

${ }^{4}$ Total differential of $(2.1)$ is: $c_{u}^{\alpha} \mathrm{d} u^{\alpha}+c_{q}^{\alpha} \mathrm{d} q-\mathrm{d} P=0$, and (2.4) is: $x_{u}^{\alpha} \mathrm{d} u^{\alpha}+x_{u}^{\beta} \mathrm{d} u^{\beta}+x_{u}^{\gamma} \mathrm{d} u^{\gamma}+\left(x_{q}^{\alpha}+x_{q}^{\beta}+x_{q}^{\gamma}+\mathrm{d} q\right)-\mathrm{d} P=0$.
} 


$$
\begin{gathered}
{\left[\begin{array}{cccc}
1 & 0 & 0 & x^{\alpha} \\
0 & 1 & 0 & x^{\beta} \\
0 & 0 & 1 & x^{\gamma} \\
x^{\alpha} & x^{\beta} & x^{\gamma} & x_{q}
\end{array}\right]\left[\begin{array}{c}
\mathrm{d} u^{\alpha} \\
\mathrm{d} u^{\beta} \\
\mathrm{d} u^{\lambda} \\
\mathrm{d} q
\end{array}\right]=\left[\begin{array}{c}
1 \\
-\delta \\
-1 \\
0
\end{array}\right] \mathrm{d} p} \\
\text { where } x_{q}=x_{q}^{\alpha}+x_{q}^{\beta}+x_{q}^{\gamma}=\sum x_{q}^{i} \\
x^{i}=c_{q}^{i} \\
c_{u}^{i}=e_{u}^{i}=\frac{\partial c^{i}}{\partial u^{i}}=1
\end{gathered}
$$

Equation (2.7) implies that a country will consume good $X$ until it reaches a point where the percentage increase in its utility exactly equals the percentage increase in its cost or expenditure. In Equation $(2.5)^{6}, x_{q}$ is the summation of the substitution effects, which are always negative for a normal good.

Let $\Delta$ be the negative of the slope of the global excess demand function. This represents the Marshall Lerner Condition (MLC) and the Walrasian stability implies that $\Delta>0^{7}$. Thus, $\Delta=-x_{q}+x_{u}^{\gamma} x^{\gamma}+x_{u}^{\beta} x^{\beta}+x_{u}^{\alpha} x^{\alpha}>0$, where, $x_{q}<0$.

The effect of an increase in $P$ on the relative price of the good using Cramer's Rule is:

$$
\frac{\mathrm{d} q}{\mathrm{~d} P}=\frac{x_{u}^{\gamma}+x_{u}^{\alpha}+\delta x_{u}^{\beta}}{\Delta}>0
$$

(2.8) implies that the relative price of good $X$ (when consumption is non-spatially separable) increases as the trade in $X$ increases. Note that $x_{u}^{\gamma}, x_{u}^{\alpha}, x_{u}^{\beta}$ represent each country's marginal propensity to consume ${ }^{8}$, which is always positive for normal goods.

\subsection{Case 2: Only Production Generates Pollution}

This is the case where country $\alpha$ exports raw materials to country $\gamma$ and or engages in pollution generating activeties in it since the production of good $X$ emits pollution as opposed to its consumption. This model is only an extension of Case 1 in that an emission tax,

$\pi(0<\pi<1)$, is applied, which reduces the amount of pollution generated in country $\gamma$ and the possible amount of pollution spillovers in country $\beta$.

The model is as follows:

$$
c^{\alpha}\left(q, u^{\alpha}\right)-P=0
$$

\footnotetext{
${ }^{5}$ Shephard Lemma.

${ }^{6}$ This is the substitution effect; it is assumed that $\mathrm{X}$ and $\mathrm{Y}$ are substitutable in production and consumption.

${ }^{7}$ The slope of the excess demand function is: $x_{q}-x_{u}^{\gamma} x^{\gamma}-x_{u}^{\beta} x^{\beta}-x_{u}^{\alpha} x^{\alpha}$.

The MLC is thus the negative of this and it is positive. See Bhagwati, Brecher, and Hatta [9].

${ }^{8}$ The Marginal Propensity to Consume is given by $x_{u}^{i} / e_{u}^{i}=x_{u}^{i}$, since $e_{u}^{i}=1$, from Equation (2.7).
}

$$
\begin{gathered}
c^{\beta}\left(q, u^{\beta}\right)+\delta(1-\pi) P=0 \\
c^{\gamma}\left(q, u^{\gamma}\right)+(1-\pi) P=0 \\
c^{\alpha}\left(q, u^{\alpha}\right)+c^{\beta}\left(q, u^{\beta}\right)+c^{\gamma}\left(q, u^{\gamma}\right)=0
\end{gathered}
$$

The corresponding augment after taking total differenttials and making similar assumptions as in Case 1 is:

$$
\left[\begin{array}{cccc}
1 & 0 & 0 & x^{\alpha} \\
0 & 1 & 0 & x^{\beta} \\
0 & 0 & 1 & x^{\gamma} \\
x^{\alpha} & x^{\beta} & x^{\gamma} & x_{q}
\end{array}\right]\left[\begin{array}{c}
\mathrm{d} u^{\alpha} \\
\mathrm{d} u^{\beta} \\
\mathrm{d} u^{\lambda} \\
\mathrm{d} q
\end{array}\right]=\left[\begin{array}{c}
1 \\
-\delta(1-\pi) \\
-(1-\pi) \\
0
\end{array}\right] \mathrm{d} P
$$

The effect of an increase in $P$ on the relative price of the good using Cramer's Rule is:

$$
\frac{\mathrm{d} q}{\mathrm{~d} P}=-\frac{(1-\pi) x_{u}^{\gamma}+\delta(1-\pi) x_{u}^{\beta}+x_{u}^{\alpha}}{\Delta}<0
$$

From Equation (3.5) above, it is apparent that the relative price of the good (when production is non-spatially separable) falls as trade in the pollutant increases.

\subsection{Case 3: Both Consumption and Production Generate Pollution}

This is the case where production and consumption of the pollutant are non-spatially separable. In this case, the developed country still shifts production to the developing country but imports the good for consumption and hence reduces the total amount of pollution by the production emissions. The budget equations are:

$$
\begin{gathered}
c^{\alpha}\left(q, u^{\alpha}\right)+P=0 \\
c^{\beta}\left(q, u^{\beta}\right)+\delta(2-\pi) P=0 \\
c^{\gamma}\left(q, u^{\gamma}\right)+(2-\pi) P=0 \\
c^{\alpha}\left(q, u^{\alpha}\right)+c^{\beta}\left(q, u^{\beta}\right)+c^{\gamma}\left(q, u^{\gamma}\right)=0
\end{gathered}
$$

The overspending function and the compensated demand functions remains the same as in Cases 1 and 2 . Using the same conditions and assumptions as above and totally differentiating and augmenting, gives:

$$
\left[\begin{array}{cccc}
1 & 0 & 0 & x^{\alpha} \\
0 & 1 & 0 & x^{\beta} \\
0 & 0 & 1 & x^{\gamma} \\
x^{\alpha} & x^{\beta} & x^{\gamma} & x_{q}
\end{array}\right]\left[\begin{array}{c}
\mathrm{d} u^{\alpha} \\
\mathrm{d} u^{\beta} \\
\mathrm{d} u^{\lambda} \\
\mathrm{d} q
\end{array}\right]=\left[\begin{array}{c}
-1 \\
-\delta(2-\pi) \\
-(2-\pi) \\
0
\end{array}\right] \mathrm{d} P
$$

The determinant of the above is same as before, and the effect of an increase in $P$ on the relative price of the

${ }^{9}$ Since the developing country's production of the pollutant will be affected by the emission but not consumption its budget equation is $c^{\gamma}\left(q, u^{\gamma}\right)+(1-\pi) P+P=0$, which simplifies to Equation (4.3). 
good using Cramer's Rule is:

$$
\frac{\mathrm{d} q}{\mathrm{~d} P}=-\frac{(2-\pi) x_{u}^{\gamma}+(1-\delta)(2-\pi) x_{u}^{\beta}+x_{u}^{\alpha}}{\Delta}<0
$$

From Equation (4.5) above, it is obvious that the relative price of the good (when consumption and production are both non-spatially separable) falls as the pollution generating activity increases.

\section{Comparing Results for All Cases}

This section compares the comparative static analysis for all three cases and provides intuition behind the results obtained.

If the good is non-spatially separable in consumption only (Case 1) the relative price of the good increases. If the good is non-spatially separable in production (Case 2) or non-spatially separable in both consumption and production (Case 3) the relative price of the good falls. Note that even though Cases 2 and 3 have same direction (sign) for the relative price of the good, the magnitude is higher for former than the latter case. The results therefore indicate that goods that are nonspatially separable in at least production have relatively lower relative prices.

The intuition behind the above result is that ways of restraining firms from increasing pollution emissions are more effective than ways of restraining consumers. Coupled with government regulations, specialization can enable firms find efficient ways of producing the good in order to reduce emissions considerably. Lower pollution levels cost society and firms less and this causes the global relative price of the good to fall. As there is little or no specialization in or restraint on consumption, increase trade in goods that are non-spatially separable in consumption reflects directly in the relative price of the goods. Second, relatively lower emission tax on firms in the developing country reduces the cost of production and hence the fall in the relative price of the good.

\section{Concluding Remarks}

This study investigates the direction of global relative prices during bilateral trade involving a pollutant in a multilateral context. The results suggest that increased trade in goods that generate pollution in production or in both production and consumption will reduce relative prices as opposed to goods that generate pollution in consumption only. Thus even though a good may be a pollutant, depending on how spatially separable it is, trade and specialization can still cause it's relative price to fall. This is true for the good in question even in countries that are non-participants.

\section{REFERENCES}

[1] G. Grossman and A. Krueger, "Environmental Impacts of a North American Free Trade Agreement," NBER Working Paper Series, MIT Press, Cambridge, 1991.

[2] H. X. Huang and W. Labys, "Modeling Trade and Environmental Linkages in China," International Journal of Global Issues, Vol. 4, No. 4, 2004, pp. 242-266. doi:10.1504/IJGENVI.2004.006053

[3] G. Grossman and A. Krueger, "Economic Growth and the Environment," The Quarterly Journal of Economics, Vol. 112, No. 3, 1995, pp. 353-377.

[4] K. E. McConnell, "Income and the Demand for Environmental Quality," Environment and Development Economics, Vol. 2, No. 4, 1997, pp. 383-399. doi:10.1017/S1355770X9700020X

[5] N. Khanna, "The Income Elasticity of Non-point Source Air Pollutants: Revisiting the Environmental Kutznets Curve," Economic Letters, Vol. 77, No. 3, 2002, pp. 387 392. doi:10.1016/S0165-1765(02)00153-2

[6] N. Khanna and F. Plassmann, "The Demand for Environmental Quality and the Environmental Kuznets Curve Hypothesis," Ecological Economics, Vol. 51, No. 3-4, 2004, pp. 225-236. doi:10.1016/j.ecolecon.2004.06.005

[7] S. Bandyopadhyay and B. Majumdar, "Multilateral Transfers, Export Taxation and Asymmetry," Journal of Development Economics, Vol. 73, No. 2, 2004, pp. 715-725. doi:10.1016/j.jdeveco.2003.05.001

[8] S. Bandyopadhyay and J. Munemo, "Transfers, Trade, Taxes and Endogenous Capital Flows: With Evidence from Sub-Saharan Africa," International Journal of Business and Economics, Vol. 5, No. 1, 2006, pp. 29-40.

[9] J. Bhagwati, R. Brecher and T. Hatta, "The General Theory of Transfers and Welfare: Bilateral Transfers in a Multilateral World," American Economic Review, Vol. 73, 1983, pp. 606-618.

[10] J. Bhagwati and R. Brecher, "Foreign Ownership and the Theory of Trade and Welfare," Journal of Political Economy, Vol. 89, No. 3, 1981, pp. 497-511. doi: $10.1086 / 260982$

[11] J. Bhagwati and R. Brecher, "Immiserizing Transfers from Abroad," Journal of International Economics, Vol. 13, No. 3-4, 1982, pp. 353-364. doi:10.1016/0022-1996(82)90063-0 